\title{
Detection of antineutrophil cytoplasmic antibody in a patient with L-tryptophan induced eosinophilia-myalgia syndrome
}

\author{
Ana M Cilursu, James Goeken, Richard R Olson
}

\begin{abstract}
The Center for Disease Control has received numerous reports of an eosinophilia-myalgia syndrome related to products containing Ltryptophan. The case is reported of eosinophilia-myalgia syndrome and polyneuropathy associated with myeloperoxidase specific antineutrophil cytoplasmic antibody.
\end{abstract}

\section{Case report}

A 61 year old woman presented in November 1989 with diffuse myalgias, fatigue, and a diffuse, pruritic, maculopapular rash, followed by shortness of breath. There was no history of ingestion of raw meats, recent travel, or contact with ill persons. Her only drug at the time of onset of symptoms was L-tryptophan, $1000 \mathrm{mg}$ (unknown manufacturer) at bedtime for insomnia, which she had been taking for four years. There were no known allergies.

On initial examination she was afebrile. There was diffuse muscular tenderness without weakness. Bibasilar rales were noted. Electrocardiogram monitoring showed episodes of paroxysmal atrial tachycardia. Chest radiography showed mild congestive heart failure.

The leucocyte count was $13.0 \times 10^{9} / 1$; haemoglobin $123 \mathrm{~g} / \mathrm{l}$; packed cell volume 0.37 ; and platelet count $272 \times 10^{9} / 1$. The differential count was $47 \%$ neutrophils, $33 \%$ eosinophils, $10 \%$ monocytes, and $8 \%$ lymphocytes. Erythrocyte sedimentation rate was $33 \mathrm{~mm} / \mathrm{h}$. Creatine kinase, aldolase, renal function, thyroid function, liver function, and results of urine analysis were normal. The antinuclear antibody titre was $1 / 80$ and rheumatoid factor $1 / 80$. Computed tomography of the chest, abdomen, and pelvis showed them to be normal. The tryptophan product was discontinued with prompt resolution of the eosinophilia. Paroxysmal tachycardia responded to verapamil and digoxin. She continued to complain of shortness of breath, muscle pain, and fatigue, which progressed to diffuse muscular weakness over the subsequent four weeks. She was unable to perform her daily activities and was readmitted for further evaluation.

Physical examination showed marked dependent pitting oedema. Results of cranial nerve and sensory examinations were normal. Motor strength examination showed $2 / 5$ weakness in the proximal muscles of both upper and lower extremities, $3 / 5$ weakness of the distal upper extremities, and normal strength in the distal lower extremities. She was unable to raise her head off the pillow.

Repeat leucocyte count was $10.7 \times 10^{9} / 1$; haemoglobin $153 \mathrm{~g} / \mathrm{l}$; packed cell volume 0.46 ; and platelet count $147 \times 10^{9} / 1$. Absolute eosinophil count was $0.214 \times 10^{9}$ cells $/ 1$ (normal $0-0.474 \times 10^{9}$ cells $\left./ 1\right)$. Total protein was $56 \mathrm{~g} / \mathrm{l}$; albumin $15 \mathrm{~g} / \mathrm{l}$; phosphorus $0.936 \mathrm{mmol} / \mathrm{l}$; serum sodium $129 \mathrm{mmol} / \mathrm{l}$, alkaline phosphatase $2 \cdot 72 \mu \mathrm{kat} / \mathrm{l}$, and lactate dehydrogenase $5 \cdot 45$ $\mu \mathrm{kat} / \mathrm{l}$. Renal function and results of urine analysis were normal. Arterial blood gases obtained on room air showed pH 7.42 $\mathrm{PaCO}_{2} 37$ $\mathrm{mmHg}$, and $\mathrm{PaO}_{2} 49 \mathrm{mmHg}$. Chest radiography showed small bilateral pleural effusions without evidence of congestive heart failure. Antinuclear antibody was positive (1/5120), whereas antihistone, double stranded DNA, SS-A, SS$\mathrm{B}$, anticentromere, Scl-70, anti-RNP, and cryoglobulins were all negative. Antineutrophil cytoplasmic antibody (ANCA) was positive $(1 / 320$, normal $<1 / 40)$ with a fine, irregular granular cytoplasmic staining pattern (fig 1). Confirmatory enzyme immunoassays for antimyeloperoxidase and antiproteinase 3 showed ANCA specificity for antimyeloperoxidase. No antiproteinase 3 activity was detected. Nerve conduction studies showed slowing in multiple segments with decreased peroneal continuous motor action potentials and absent sural responses; electromyography showed small, polyphasic, long duration units with early recruitment, compatible with a neuropathic process.

A right quadriceps muscle biopsy suggested severe neurogenic atrophy with secondary myopathic changes: frozen sections of skeletal muscle stained with haemotoxylin/eosin showed that $90 \%$ of the fibres were atrophic. Many of these were angular in large groups. Many cells were basophilic and others overtly necrotic. There was an increase in endomysial connective

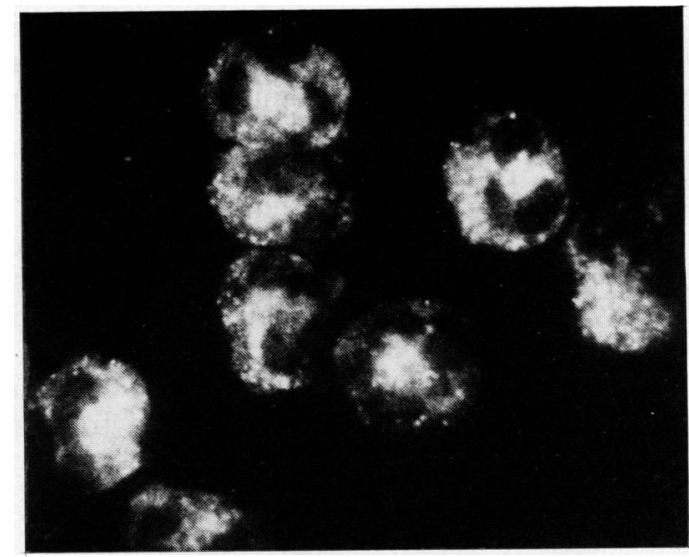

Figure 1 Antineutrophil cytoplasmic antibodystaining demonstrated on ethanol fixed human neutrophils by indirect immunofluorescent microscopy. 


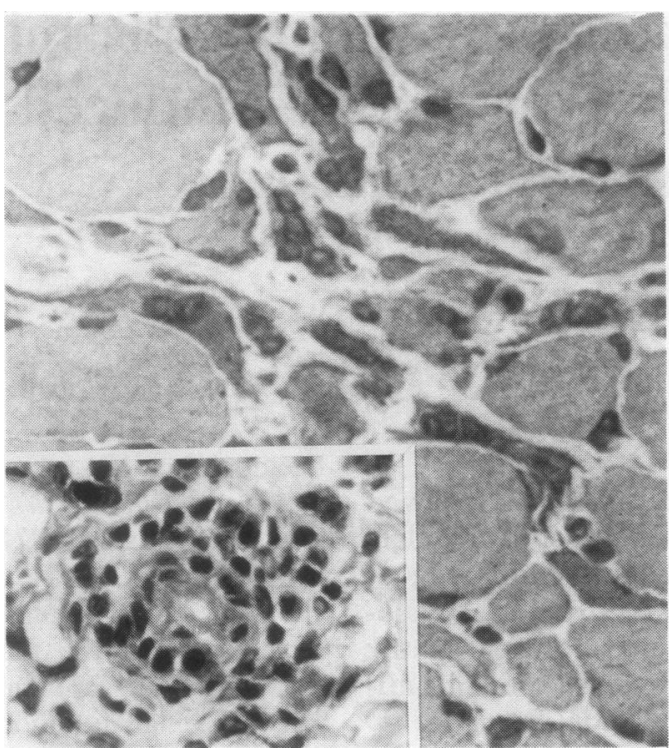

Figure 2 Normal sized fibresadmixed with groups of angular atrophic type I and type II fibres. Inset: mononuclear cell infiltrate within vessel wall and perivascular space. Novessel wall necrosis orvessel thrombosis was found.

tissue. Stains with periodic acid-Schiff reagent showed appropriate glycogen. Congo red stains were negative for amyloid. On serial section one vessel had a number of inflammatory cells within the wall and in the perivascular connective tissue (fig 2). There was no evidence of thrombosis or necrosis of the vessel wall. Nasal mucosal biopsies did not show any evidence of granulomatous inflammation. Stomach and small bowel biopsies were negative for Ménétrier's disease.

Progressive worsening of respiratory muscle function necessitated the use of ventilatory support. Treatment was started with methylprednisolone (Solumedrol), $20 \mathrm{mg}$ every eight hours, with improvement in respiratory inspiratory force and weaning from mechanical ventilatory support. The weakness in her upper and lower extremities increased, prompting empirical treatment with cyclophosphamide $2 \mathrm{mg} / \mathrm{kg}$ daily. This was temporarily withheld during an episode of bacterial pneumonia. With this regimen ventilatory support was not required and signs of gradual improvement in muscle strength were seen. After a complicated course she was finally discharged and continued to receive prednisone ( $35 \mathrm{mg}$ daily) and cyclophosphamide (100 mg daily).

\section{Discussion}

The use of L-tryptophan has been implicated in a syndrome characterised by subacute onset of myalgia, fatigue, respiratory symptoms, including cough, dyspnoea, and hypoxaemia, skin rash (described as maculopapular, vesicular, or urticarial), and frank muscle weakness. ${ }^{1}$ Both marked peripheral eosinophilia and perivascular, eosinophilic inflammatory infiltrates are striking findings. ${ }^{1}$

The incidence of antinuclear antibody production in eosinophilia-myalgia syndrome is unknown. Previously reported cases have not shown evidence of high titre antinuclear antibody, ${ }^{2-5}$ though Varga et al reported one patient with a titre of $1 / 2560$ in association with diffuse fasciitis and L-tryptophan use. ${ }^{5}$ The development of polyneuropathy and progession of muscle weakness despite withdrawal of the offending agent and resolution of the eosinophilia has previously been noted in eosinophiliamyalgia syndrome. ${ }^{3}$ This suggests that the neuropathic process can progress independently of circulating blood concentrations of Ltryptophan or eosinophilia.

Antineutrophil cytoplasmic antibody specificity has been the subject of two international workshops (Copenhagen, 1988; Leiden, 1989) and thus far, two major specificities have been identified: antimyeloperoxidase and antiproteinase $3 .^{6-9}$ These have been mutually exclusive in nearly all reported studies. ${ }^{10}$ The disease associations of ANCA have been the subject of a number of reports, but systemic vasculitides and glomerulonephritis characterised by segmental necrosis, epithelial crescent formation, and little or no immune deposits are most commonly identified with these autoantibodies. Several early reports closely linked ANCA to Wegener's granulomatosis. ${ }^{11} 12$ The sensitivity and specificity of ANCA in active Wegener's granulomatosis have been reported to be as high as $93 \%$ and $97 \%$ respectively. ${ }^{13}$ In most cases of Wegener's granulomatosis antiproteinase 3 ANCA specificity has been found, though in a smaller number of cases antimyeloperoxidase has been identified. ${ }^{814-17}$ Positive ANCAs have also been reported in idiopathic necrotising segmental crescentic glomerulonephritis, polyarteritis (both classical and microscopic variants), allergic granulomatosis of Churg-Strauss, and cystic fibrosis with vasculitis. ${ }^{6} 81018-21$ In patients with idiopathic necrotising segmental crescentic glomerulonephritis, both with and without associated systemic vasculitis, antimyeloperoxidase is the most commonly reported specificity; however, in some series antiproteinase 3 has been found in a smaller number of patients with this diagnosis. ${ }^{10}$ Even though a large number of other rheumatic diseases do not appear to be associated with ANCA, ${ }^{6}$ its presence in this patient with tryptophan associated eosinophiliamyalgia syndrome broadens the spectrum of possible associations.

The authors are indebted to Dr Robert L Schelper for preparing the photomicrographs and to Paula Thomas for her secretarial expertise.

Kilbourne EM, Swygert LA, Philen RM, et al. Interim guidance on the eosinophilia-myalgia syndrome. Ann Inter Med 1990; 112: 85-6.

2 Eosinophilia-myalgia syndrome-New Mexico $M M W R$ 1989; 38: 765-7.

3 Eosinophilia-myalgia syndrome and L-tryptophan-containing products-New Mexico, Minnesota, Oregon and New York. MMWR 1989; 38: 785-8.

4 Flannery MT, Wallach PM, Espinoza LR, Dohrenwend MP, Moscinski LC. A case of the eosinophilia-myalgia syndrome associated with use of an L-tryptophan product. Ann Intern Med 1990; 112: 300-1.

5 Varga J, Peltonen J, Uitto J, Jimenez S. Development of diffuse fasciitis with eosinophilia during L-tryptophan treatment: demonstration of elevation type I collagen gen expression in affected tissues. Ann Intern Med 1990; 112 34451 .

6 Falk RJ, Jennette JC. Anti-granulocyte cytoplasmic autoantibodies with specificity for myeloperoxidase in patients 
with systemic vasculitis and idiopathic necrotizing and cresentic glomerulonephritis. $N$ Engl $\mathcal{F}$ Med 1988; 318: 1651-7.

7 Ludemann J, Gross WL. Anti-neutrophil cytoplasm antibodies in Wegener's granulomatosis recognize an elastinolytic enzyme. $\mathcal{E}$ Exp Med 1990; 171 : 357-62.

8 Jennette JC, Falk RJ. Anti-neutrophil cytoplasmic antibodyassociated glomerulonephritis and vasculitis. Am $\mathcal{f}$ Pathol 1989; 135: 921-30.

9 Niles JL, McCluskey RT, Ahamad MF, Arnaout MA. Wegener's granulomatosis autoantigen is a novel neutrophi Wegener's granulomatosis autoantigen is a nov
serine proteinase. Blood 1989; 74: 1888-93.

10 Jennette JC, Falk RJ. Antineutrophil cytoplasmic autoantibodies and associated diseases: a review. Am $\mathcal{F}$ Kidney Dis $1990 ; 15: 517-29$

11 Van Der Woude FJ, Rasmussen N, Lobatto S, et al. Autoantibodies against neutrophils and monocytes: tool for diagnosis and marker of disease activity in Wegener's granulomatosis. Lancet 1985; i: 425-9.

12 Ludemann G, Gross WL. Autoantibodies against cytoplasmic structures of neutrophil granulocytes in Wegener's granulomatosis. Clin Exp Immunol 1987; 69: 350-7.

13 Cohen Tervaert JW, Van Der Woude FJ, Fauci AS, et al. Association between active Wegener's granulomatosis and anticytoplasmic antibodies. Arch Intern Med 1985; 149: 2461-5.
14 Nölle B, Specks U, Lüdemann J, Rohrbach MS, DeRemee RA, Gross WL. Anti-cytoplasmic autoantibodies: their diagnostic value in Wegener's granulomatosis. Ann Intem Med 1989; 111: $28-40$.

15 Andrassy K, Koderisch J, Waldherr R, Rufer M. Diagnostic significance of anti-cytoplasmic antibodies (ACPA/ANCA) in detection of Wegener's granulomatosis and other forms in detection of Wegener's granulomatosis
of vasculitis. Nephron 1988;49:257-8.

16 Gans ROB, Goldschmeding R, Donker AJM, et al. Neutrophil cytoplasmic autoantibodies and Wegener's granulomatosis Lancet 1989; i: 269-70.

17 Case 251989 , Case records of the Massachusetts General Hospital. NEngl f Med 1989; 320: 1677-86.

18 Savage COS, Winearls CG, Jones S, Marshall PD, Lockwood CM. Prospective study of radioimmunoassay for antibodies against neutrophil cytoplasm in diagnosis of systemic vasculitis. Lancet 1987; i: 1389-93.

19 Venning M, Arfeen S, Bird A. Antibodies to neutrophil cytoplasmic antigen in systemic vasculitis. Lancet 1987; ii: 850 .

20 Nässberger $L$, Sjöholm A, Bygren $P$, Thysell $H$, HøjerMadsen M, Rasmussen N. Circulating anti-neutrophil cytoplasm antibodies in patients with rapidly progressive glomerulonephritis and extracapillary proliferation. $\mathcal{J}$ Inter Med 1989; 225: 191-6.

21 Finnegan MJ, Hinchcliffe J, Russel-Jones D, et al. Vasculitis complicating cystic fibrosis. Qf Med 1989; 267: 609-21. 
Corrected serum calcium and full blood count remained normal. A drug induced central nervous system toxicity syndrome was diagnosed by a psychiatrist, and thioridazine reduced the frequency and disturbing effect of the hallucinations. A brain computed tomographic scan was normal.

Studies of patients with Paget's disease treated with pamidronate have consistently shown a transient fall in serum calcium and phosphate, which are seldom of clinical significance and are associated with a decline in urinary calcium excretion and an increase in plasma parathyroid hormone levels. ${ }^{6}$ Transient haematological changes and fevers have also been reported ${ }^{4}$ after both oral and IV pamidronate, possibly mediated through direct or indirect effects on mononuclear phagocytes, resulting in the activation of cytokines. ${ }^{3}$ The mechanism underlying hallucinations in this patient is unknown but is considered unlikely to be due to alterations in serum calcium concentrations.

Adverse psychiatric reactions to biphosphonates appear to be rare, although etidronate has previously been reported to cause confusion (Committee on Safety of Medicines, personal communication). It is recommended that the mental state of patients given high dose infusions of pamidronate for Paget's disease should be monitored closely after their treatment.

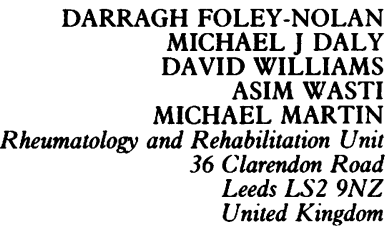

1 Gallacher S J, Boyce B F, Patel U, Jenkins A, Ralston S H, Boyle I T. Clinical experience with pamidronate in the treatment of Paget's disease
2 Morton A R, Cantrill J A, Tracy A E, Howell A, Davies M, Anderson D C. Comparison of single dose versus daily intravenous amin hydroxypropylidene-1,1 biphosphonate (APD) for the management of the hypercalcaemia of malignancy. BMF 1988; 296: 390-1.

3 Harinck H I J, Papapoulas G E, Blanksma H J, Moolenar A J, Vermey P, Byvoet O I M. Moolenar A J. Vermey $\mathrm{P}$, Byvoet $\mathrm{O} \mathrm{L} \mathrm{M}$. Paget's disease of bone: early and late response to three different modes of treatment with aminohydroxypropylidene 1 1

4 Thiebaud D, Jaeger $P$, Gobelet C, Jacquet A F A single infusion of biphosphonate $\mathrm{AH}$ Pr BP (APD) as treatment of Paget's disease of bone. Am F Med 1988; 85: 207-12.

5 Cantrill J A, Anderson D C. Treatment of Paget' disease of bone. Clin Endocrinol 1990; 32 507-18.

6 Thiebaud D, Jaeger D, Burckhardt P. Paget's disease of bone treated in five days with : $45-52$

\section{Correction}

Sir: We are writing to correct an inadvertent error in our manuscript entitled 'Detection of antineutrophil cytoplasmic antibody in a patient with L-tryptophan induced eosinophilia-myalgia syndrome', which appeared in volume 50 of the Annals last year. ${ }^{1}$ The caption of fig 1 , on page 817 , stated that the antineutrophil cytoplasmic antibody stain shown was demonstrated on ethanol fixed human neutrophils. This photomicrograph was actually of the antineutrophil cytoplasmic antibody indirect immunofluorescence on formalin-acetone fixed human neutrophils. This is of importance because the antineutrophil cytoplasmic antibody (ANCA) specificity documented by enzyme immunoassay was for myeloperoxidase, which typically produces a perinuclear/nuclear staining pattern on ethanol fixed neutrophils rather than the granular cytoplasmic staining which is depicted. This pattern on ethanol fixed neutrophils is associated with antiproteinase 3 specificity in about $\mathbf{8 5 - 9 0 \%}$ of cases. An assay for antiproteinase 3 was negative in our patient, who also had a high titre of antinuclear antibody present at the time the ANCA was detected. Myeloperoxidase ANCA are difficult to detect on ethanol fixed neutrophils in the presence of antinuclear antibodies; therefore, we used the formalin-acetone fixation. technique, which prevents the translocation of myeloperoxidase from the primary granules in the neutrophil cytoplasm to the nucleus when the nuclear membrane is lysed. When this technique is used, both types of ANCA demonstrate the staining pattern shown. In the absence of antinuclear antibodies ethanol fixed neutrophils are then used to rescreen the patient's serum and if the pattern converts to a perinuclear/nuclear one, myeloperoxidase specificity is present in $90 \%$ of cases. When antinuclear antibodies obscure the ANCA pattern a secondary assay such as the enzyme linked immunosorbent assay (ELISA) we used must be employed to identify the specificity of the ANCA present.

ANA CILURSU The Atlantic City Medical Center Department of Medical Education 1925 Pacific Avenue Atlantic City, NF 08401, USA

JAMES A GOEKEN
Department of Pathology
Division of Immunopathology
University of Iowa Hospitals and Clinics
Iowa City, IA 52242, USA
RICHARD R OLSON
Department of Internal Medicine
University of Iowa Hospitals and Clinics
Iowa City, IA 52242, USA

1 Cilursu A M, Goeken J, Olson R R. Detection of antineutrophil cytoplasmic antibody in patient with $\mathrm{L}$-tryptophan induced eosinophiliamyalgia syndrome. Ann Rheum Dis 1991; 50: 817-9. 